\title{
Direct-Write Bioprinting Approach to Construct Multilayer Cellular Tissues
}

\author{
Elahe Masaeli ${ }^{1,2 *}$ and Christophe Marquette ${ }^{2 *}$ \\ ${ }^{1}$ Department of Cellular Biotechnology, Cell Science Research Center, Royan Institute for Biotechnology, ACECR, Isfahan, \\ Iran, ${ }^{2} 3 d$.FAB, Univ Lyon, Université Lyon1, CNRS, INSA, CPE-Lyon, ICBMS, UMR 5246, Bat. Lederer, Villeurbanne, France
}

\section{OPEN ACCESS}

Edited by:

Tim B. F. Woodfield,

University of Otago, New Zealand

Reviewed by:

Aleksander Skardal,

The Ohio State University,

United States

Jianxun Ding,

Changchun Institute of Applied

Chemistry (CAS), China

*Correspondence:

Elahe Masaeli

elahe.masaeli@royaninstitute.org

Christophe Marquette

christophe.marquette@univ-lyon1.fr

Specialty section:

This article was submitted to

Biomaterials,

a section of the journal

Frontiers in Bioengineering and

Biotechnology

Received: 16 September 2019

Accepted: 23 December 2019

Published: 21 January 2020

Citation:

Masaeli E and Marquette C (2020) Direct-Write Bioprinting Approach to

Construct Multilayer Cellular Tissues.

Front. Bioeng. Biotechnol. 7:478.

doi: 10.3389/fbioe.2019.00478
As a cellular-assembly technique, bioprinting has been extensively used in tissue engineering and regenerative medicine to construct hydrogel-based three-dimensional (3D) tissue-like models with prescribed geometry. Here, we introduced a unique direct-write bioprinting strategy to fabricate a bilayer flat tissue in a hydrogel-free approach. A printed retina pigmented epithelium layer (RPE) was applied as living biopaper for positioning a fibroblast layer without using any hydrogel in bioink. We adjusted the number of cells in the inkjet droplets in order to obtain a uniform printed cell layer and demonstrated the formation of a bilayer construct through confocal imaging. Since our printing system introduced low levels of shear stress to the cells, it did not have a negative effect on cell survival, although cell viability was generally lower than that of control group over 1 week post-printing. In conclusion, our novel direct-write bioprinting approach to spatiotemporally position different cellular layers may represent an efficient tool to develop living constructs especially for regeneration of complex flat tissues.

Keywords: tissue regeneration, cell layer, inkjet bioprinting, living biopaper, tissue complexity

\section{INTRODUCTION}

Current regenerative medicine systems aim to develop three dimensional (3D) engineered constructs mimicking, as much as possible, the natural tissues found in human body. In this regard, different biofabrication approaches, based on lithography, liquid extrusion and mechanical deposition, were developed to precisely create 3D tissue scaffolds with controlled composition, microarchitecture and geometry (Mota et al., 2015; Moroni et al., 2018).

Most of the aforementioned techniques rely on the active role of biomaterials as structural units and do not incorporate cells during the manufacturing process. Consequently, following the fabrication process, a subsequent cell seeding procedure on/within scaffolds is required. In particular, due to the high complexity of living tissues, multiple cells shall be seeded in the same scaffold, using various complicated seeding methods (perfusion, diffusion, rotational seeding) (Van Den Dolder et al., 2003; Nieponice et al., 2008). In some complex layered structures, such as skin, cornea, retina, and trachea, achieving an effective cellular seeding of the architecture is a considerable challenge. Another challenging group of tissue is the osteochondral joint, where the seeding is even more difficult because of the complexity of the interfaces between cellular layers (Atala et al., 2012). To address these challenges, several methods, such as microencapsulation (Orive et al., 2015), loading cells into microfibers/beads (Matsunaga et al., 2011; Onoe and Takeuchi, 2015) and preparation of cell-laden hydrogels are currently under study to incorporate cells into the structure and use these materials as building blocks in top-down tissue engineering approaches.

Bioprinting, as a well-known additive manufacturing process, aimed at the direct construction of cell-laden tissues by utilizing one of the above-mentioned biofabrication approaches. Bioprinting 
is capable of either patterning materials in a well-defined design and localizing biological components, such as living cells with a controlled geometry to meet clinical needs (Gao et al., 2016; Mandrycky et al., 2016). In doing so, one of the main limitations of typical tissue engineering methods, i.e., control of the cells seeding within scaffold for mimicking complex tissues, can be overcame.

There are two major bioprinting approaches in literatures: hydrogel-based and hydrogel-free bioprinting. In the first approach, cells are printed within a hydrogel network as a supportive matrix for cell proliferation and maturation, while in the second one, cell suspensions are directly used as bioink. This hydrogel-free approach allows cells to aggregate and secrete their own extracellular matrix (ECM) to hold them together (Jakab et al., 2008; Ozbolat, 2015). Nevertheless, since proliferation is low in these scaffold-free systems, starting with a high cell population is mandatory to reduce time of tissue maturation (Ozbolat, 2015).

Usually, in hydrogel-free systems, cell aggregates or tissue spheroids are accurately positioned through one of most common bioprinting approaches, such as inkjet (Daly and Kelly, 2019), laser guidance (Barron et al., 2004), and extrusion bioprinting (Norotte et al., 2009; Jakab et al., 2010; Pourchet et al., 2017). In the meantime, there is some efforts to directly deposit cell suspension into pre-define patterns (Xu et al., 2005; Calvert, 2007), but to the best of our knowledge, controlling layer by layer the position as well as density and uniformity of seeded cells into $3 \mathrm{D}$ structures was not yet optimized. The purpose of this study is to facilitate and control the transfer of two different cell types in a layered structure. An inkjet bioprinting system was applied to directly print cells without carrier material in a predefined design. Gelatin methacryloyl (GelMa) hydrogel coated cover glass slides were used as cell-adhesive culture substrate, also called "biopaper" on which cells were bioprinted. Using this method we were able to produce complex multilayer cellular models especially useful for soft tissue engineering.

\section{MATERIALS AND METHODS}

\section{Printing System}

The inkjet bioprinting system has been applied in our earlier study and is briefly summarized here (Masaeli et al., 2019). This is a piezoelectric inkjet dispenser S3 sciFLEXARRAYER (Scienion AG, Germany) composed of two key subsystems: a $3 \mathrm{D}$ stage movement system controlled by a stage controller (accuracy $5 \mu \mathrm{m}$ ) and a droplet deposition system controlled by a pulse generator and equipped with an $80 \mu \mathrm{m}$ diameter glass nozzle, used here as a non-contact print head. The cell droplet generation system is employed to generate building blocks (i.e., cells in culture media with volume of $300 \mathrm{pL}$ ), guided by a computer-aided design software. A stroboscopic camera allows visual monitoring to adjust piezo voltages and pulse durations for reliable droplet ejection. This system provides precise spatial control over droplet deposition. The obtained accuracy of the droplet positioning is $5 \mu \mathrm{m}$.

Since, the height of printer glass nozzle is less than depth of tissue culture plates, we designed and $3 \mathrm{D}$ printed a silicon cylinder part, insert in each well in order to reduce the distance between the printing head and the cover glass (drop distance) to an optimum of $1 \mathrm{~mm}$ (Figure 2A). This leads the drops to be accurately deposited and not sprayed over the cover glass surface.

\section{Preparation of GelMa Coated Slides}

A thin layer of GelMa was coated on circular glass coverslips ( $0.5 \mathrm{~mm}$ thick, $17 \mathrm{~mm}$ diameter, T\&Q, China), and subsequently used as biopaper substrate for bioprinting. To prepare this GelMa layer, the following protocol was implemented. Irgacure D2959 (Sigma, France), used as a photoinitiator, was dissolved in dimethyl sulfoxide (DMSO) at a concentration of $1.5 \%(\mathrm{w} / \mathrm{v})$. Then, coating solution was prepared by dissolving GelMa powder (Sigma, France) at a concentration of $0.2 \% \mathrm{w} / \mathrm{v}$ in the previously prepared Irgacure solution, degassing under vacuum for $10 \mathrm{~min}$ to eliminate bubbles and finally heating for $30 \mathrm{~min}$ at $55^{\circ} \mathrm{C}$. After setting the glass substrate on the spin coater vacuum holder, 200 $\mu \mathrm{L}$ of GelMa coating solution was dropped and spin-coated at 3,000 rev. $\mathrm{min}^{-1}$ for $30 \mathrm{~s}$ using a WS-650MZ spin coater (Laurell, USA). Finally, in order to obtain fully cross-linked coating, the spin coated slides were exposed to $32 \mathrm{~W}$ UV radiation $(254 \mathrm{~nm})$ at a distance of $14 \mathrm{~cm}$ for $30 \mathrm{~min}$ (BLX-E254, Bio-Link, Fisher Biotec, Australia).

\section{Cells' Printing}

Green fluorescent protein (GFP)-expressing fibroblasts (NIH3T3/GFP, AKR-214, Cell Biolabs Inc., US) were expanded and suspended in D-MEM (high glucose) (Gibco, France) supplemented with $10 \%(\mathrm{v} / \mathrm{v})$ fetal bovine serum (FBS, Gibco, France), $0.1 \mathrm{mM}$ MEM non-essential amino acids (NEAA, Invitrogen, France), 2 mM L-glutamine (Gibco, France) and 1\% (w/v) penicillin/streptomycin (10,000 U/mL) (Gibco, France).

Retina pigmented epithelium (RPE) cells (ARPE-19, ATCC, France) were expanded and suspended in DMEM-F12 medium (ATCC, France) supplemented with $10 \%(\mathrm{v} / \mathrm{v})$ fetal bovine serum (FBS, Gibco, France), and 1\% (v/v) penicillin/streptomycin (10,000 U/mL) (Gibco, France).

All cells were culture in a $37^{\circ} \mathrm{C}$ incubator in the presence of $5 \% \mathrm{CO}_{2}$.

Just before bioprinting, cells were trypsinized $[0.25 \%(\mathrm{v} / \mathrm{v})$ trypsin-EDTA (ThermoFisher, France)], and counted. Cell suspensions $\left(2.3 \times 10^{7}\right.$ and $6.4 \times 10^{7}$ cells $/ \mathrm{mL}$ for NIH3T3 and RPE, respectively) were directly used as bioink within the inkjet process using a direct-write bioprinting strategy. RPE cells were bioprinted first $(18 \times 18$ spots array, $800 \mu \mathrm{m}$ spot-to-spot distance, $15 \mathrm{~nL}$ per spot) on GelMa coated slide, adhered and cultured for 1 week. Then, NIH3T3 cells were bioprinted onto mature RPE layer following a predefined pattern. In this step, a dot pattern of 160 deposition locations of $15 \mathrm{~nL}$ drops were dispensed within an array of $18^{*} 18$ spots $(800 \mu \mathrm{m}$ spot-to-spot distance) (Figure 2B). Images of the printed dots were recorded with an Olympus IX51 microscope.

\section{Cell Viability}

The post-printing cellular viability was assessed using the TOX8 Resazurin-based in vitro Toxicology Assay Kit (Sigma, France), on media collected 1, 3, and 5 days after bioprinting, according 
to the manufacturer's instructions. In Brief, kit mix, $10 \%(\mathrm{v} / \mathrm{v})$ of the final volume, was added to each sample and incubated during $2 \mathrm{~h}$ at $37^{\circ} \mathrm{C}$. Resazurin (non-fluorescent) to resorufin (fluorescent) conversion was measured fluorometrically (Ex/Em $=600 / 690 \mathrm{~nm}$ ) using an Infinite M200 Microplate reader (TECAN, France). Manually seeded cells with similar density were used as control group. The assays were performed three times in all experiments to assess variability.

\section{Actin Cytoskeleton Staining}

In order to visualize F-actin structures within cells after bioprinting, constructs were fixed with $3.7 \%(\mathrm{v} / \mathrm{v})$ paraformaldehyde diluted in phosphate buffer saline (PBS, Invitrogen, France) for $30 \mathrm{~min}$ at room temperature, permeabilized with $0.1 \%(\mathrm{v} / \mathrm{v})$ TritonX-100 for $10 \mathrm{~min}$, and finally stained with 5 units of Alexa Fluor 546 phalloidin (Molecular Probes, France) for $40 \mathrm{~min}$ at room temperature. Samples were counterstained with the nuclear stain, $4^{\prime}, 6$ diamidino-2-phenylindole (DAPI, Invitrogen, France) (0.1 $\mathrm{mg} / \mathrm{mL}$ ) and imaged by confocal microscopy. Images were taken at the Center Technologique des microstructures (University of Lyon, France) using a Zeiss LSM800 confocal microscope.

\section{Statistical Analysis}

Statistical analysis was carried out using one-way analysis of variance (ANOVA) and independent sample $t$-test to compare the viability of bioprinted cell and control group. A value of $p$ $\leq 0.05$ was considered statistically significant.

\section{RESULTS AND DISCUSSION}

The classical bioprinting strategy to create multicellular tissue models is based on designed deposition of different cell sources within a hydrogel (i.e., cell-laden hydrogel). These models normally lack uniformity of printed cells and thereupon cannot completely mimic tissue structure. Furthermore, depending on the carrier hydrogel viscosity, cells might experience high amounts of shear stress that may unfavorably affects viability, signaling and generate phenotype drifting (Blaeser et al., 2016; Chimene et al., 2016). Direct printing of living cells without hydrogel inks has then here a number of obvious advantages, such as high cell viability but also the fact that in the absence of carrier, cells will freely produce their own extracellular matrix (ECM) and form 3D structures recapitulating physiological tissues' organization (Ozbolat, 2015).

Based on this idea, we applied a direct-write bioprinting setup to reproduce a bilayer construct in a hydrogel-free manner (Figure 1). The technique is based on a programmable noncontact piezoelectric inkjet bioprinter with a resolution of $5 \mu \mathrm{m}$ and a minimum deposition volume of $300 \mathrm{pL}$. Such a system has been frequently applied in researches, especially for ultra-low volume liquid handling of nanoparticles (Scherbahn et al., 2016), drugs (Tronser et al., 2018), and biomolecules, such as proteins (Kilb et al., 2019) and antibodies (Marquette et al., 2012; Schulz et al., 2019).

In this bioprinting process, a crucial components, named biopaper, acts as a biomimetic tissue fusion-permissive substrate with appropriate biocompatibility and mechanical stability. In different studies, gelatin-derived hydrogels (Imani et al., 2011; Pirlo et al., 2012; Colosi et al., 2016) as well as cell-laden

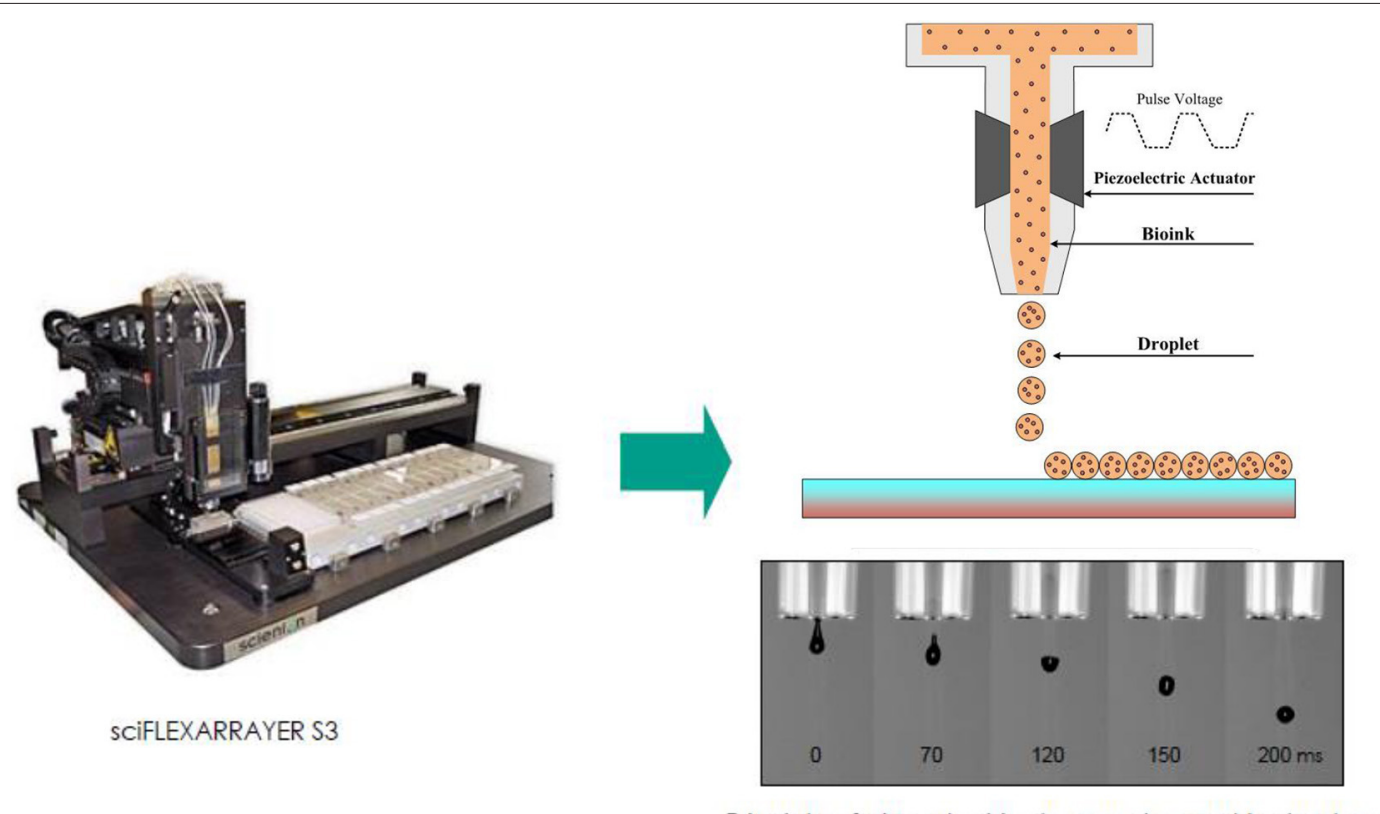

Principle of piezoelectric drop on demand technology

FIGURE 1 | A schematic illustration of direct-write bioprinter setup (www.scienion.de). 
bioinks (Nichol et al., 2010; Bertassoni et al., 2014) have been applied as biopaper. In the present study, a 5-20 $\mu \mathrm{m}$ thick GelMa layer [measured using confocal 3D optical profilometer (NanoJura, France)] was coated on glass slide and used as biopaper to enhance the adhesion of the first layer of printed cells. GelMa is a photopolymerizable material composed of modified natural ECM components, containing then significant amount of matrix metalloproteinase and focal adhesion sequences, beneficial to promote cellular functions (Yue et al., 2015). We also previously showed that printed cells were viable and proliferate on GelMa layer over 1-week culture time, and that GelMa coating probably guides cells to form tight junction monolayer sheet (Masaeli et al., 2019).

The cell-printing system was first characterized with NIH3T3 cell suspension using the GelMa coated glass slide as printing support. Figures 2A,B depict the dot pattern design which was used to experimentally evaluate size and distance between printed dots (i.e., printing resolution). For sake of comparison, a low viscosity alginate solution was used in addition to the cell suspension. Analysis of captured images showed that average dot diameters were $426 \pm 15$ and $629 \pm 10 \mu \mathrm{m}$ for alginate and cell solutions, respectively (Figures 2C,D). Average drop-todrop distances were found to be $376 \pm 34$ and $210 \pm 12 \mu \mathrm{m}$ for alginate and printed solutions, respectively. These measurements helped us determine the final resolution of our inkjet bioprinting system. Indeed, it is well-known that the final resolution of an inkjet printing process can be quite different from the theoretical resolution since the surface chemistry and the ink composition both lead to droplet spreading variations (Binder et al., 2011). As a consequence here, even if the printer should be able to reliably print with resolution of $5 \mu \mathrm{m}$, the obtained depositions expanded by $47 \%$ between alginate and cell solution and their distance therefore decreased by $44 \%$.

Although some researchers believe that low cell density of inkjet bioprinting is one of its main disadvantages (Holzl et al., 2016; Derakhshanfar et al., 2018), here we were able to use high cell population in each drop $\left(2.3 \times 10^{7}\right.$ cells $\left./ \mathrm{mL}\right)$, probably thanks to the low viscosity $\left(1.00 \mathrm{E}^{-03} \mathrm{~Pa} \cdot \mathrm{s}\right)$ of the bioink cell suspension. Especially for creation of some tissues, such as endothelium, printing with high initial cell densities is essential because cells should be in physical contact with each other. Also, high density of cells is required for tissue engineering when cells with limited to no proliferative potential (such as photoreceptors and chondrocytes...) are introduced into bioprinter (Guillotin et al., 2010).

Another concern related to bioink rheological behavior is that inkjet nozzle could be clogged or generating too much shear stress during cell deposition (Zhang and Zhang, 2015;

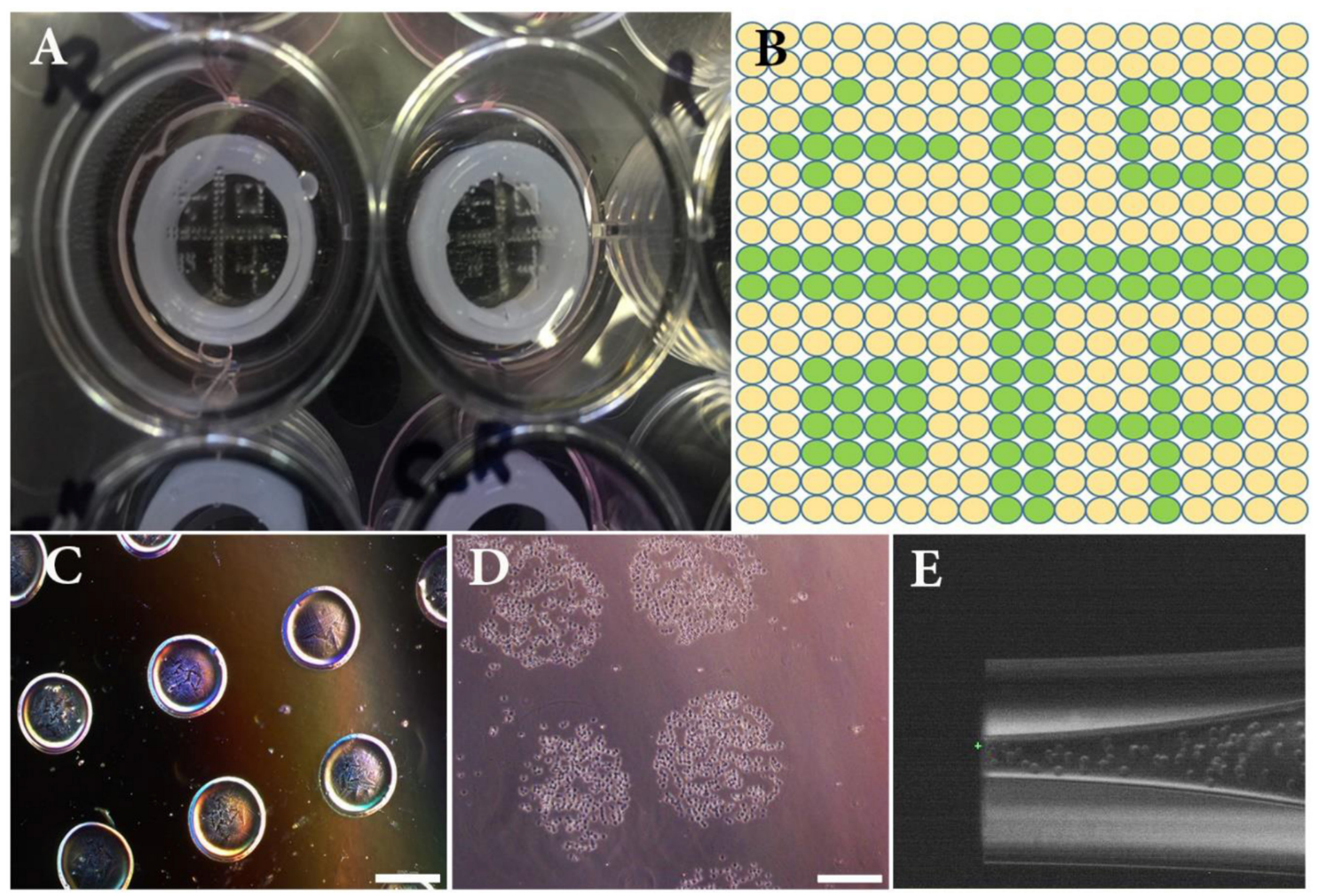

FIGURE 2 | (A) Overview of the experimental set-up composed of a 12-well plate, 3D printed silicone positioning systems, GelMa coated circular glass slides and printed patterns of NIH3T3 cells. (B) Overview of the theoretical printing patterns in printer software. (C) Printed drops (15 nL) of alginate hydrogel used to setup size and distance between droplets. (D) Printed drops (15 nL) of NIH3T3 immediately after bioprinting. (E) Close-up image of the bioprinted nozzle filled with NIH3T3 cells. Scale bars: $500 \mu \mathrm{m}$. 

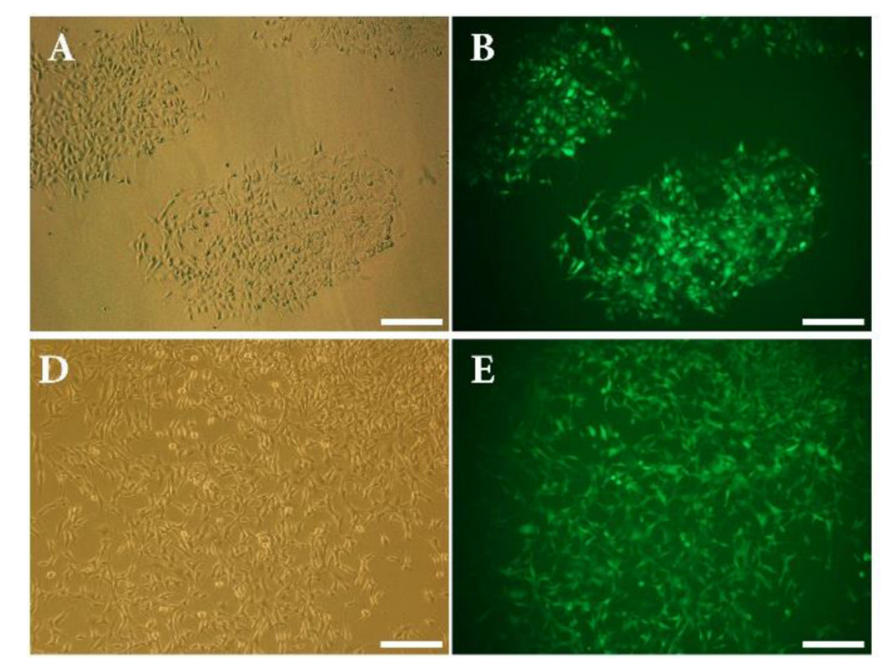

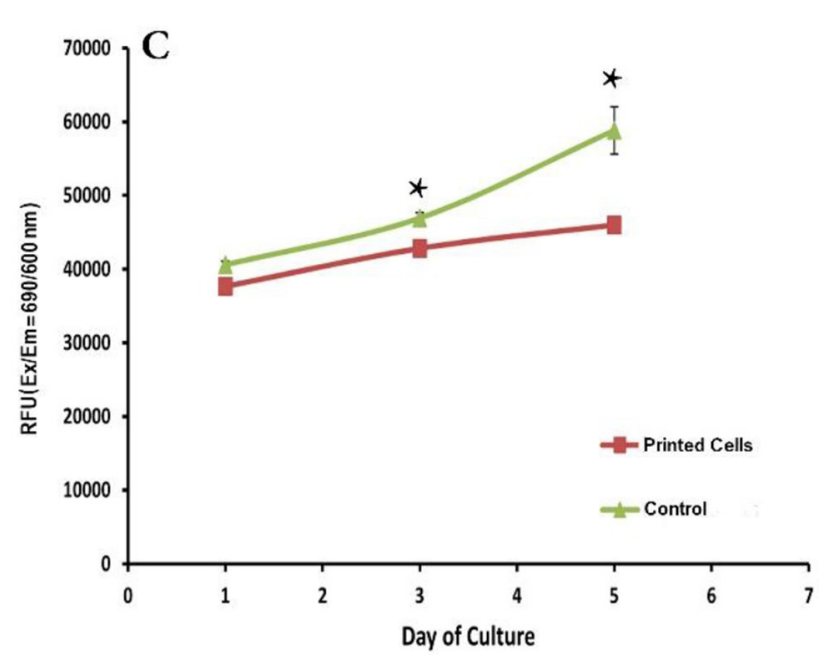

FIGURE 3 | (A,B) Phase contrast and fluorescent images showing attachment of bioprinted NIH3T3 cells 1 day after printing. (C) Viability of bioprinted NIH3T3 cells during 5 days after printing. (D,E) Phase contrast and fluorescent images showing growth of bioprinted NIH3T3 cells 5 days after printing. Asterisks represent significant difference at $p \leq 0.05$. Scale bars: $200 \mu \mathrm{m}$.

Chimene et al., 2016; Bishop et al., 2017). Attempts have been made to overcome these issues by using low viscosity bioinks. For example, Desimone et al. (2015) reduced shear stress inside nozzle by using low viscosity solutions of recombinant spider silk instead of native silk. Colosi et al. prepared a blend of GelMa and alginate as low viscosity $(0.08 \mathrm{~Pa} / \mathrm{s})$ ink and used it for printing heterogeneous $3 \mathrm{D}$ tissue constructs. They believed that printing with low viscosity bioinks shall enhance biological properties and resulting in tissue functions recapitulation (Colosi et al., 2016).

In the present work, not only no clogging was evidenced within the capillary nozzle (Figure 2E), but also, the calculated maximum shear stress [calculated using the nozzle geometry and a viscosity of $1.00 \mathrm{E}^{-03} \mathrm{~Pa} \cdot \mathrm{s}$ : Wall Shear rate: $1.31 \mathrm{E}^{+08}$ $\mathrm{s}^{-1}$; Wall Shear stress: $1.31 \mathrm{E}^{+05} \mathrm{~Pa}$ (3d.FAB, 2018)] was much lower than the previously reported acceptable stress limit (Malda et al., 2013).

We have thus successfully replaced bioprinting ink with cell suspension and set size and distances between inkjet droplets. The next crucial step toward the introduction of this directwrite bioprinting approach is the demonstration of attachment and growth of bioprinted cells over time. This was performed by following cell behavior for 5 days post-bioprinting. Figures 3A,B depict images of two adjacent depositions using contrast phase and fluorescent microscopy, respectively. As a matter of fact, bioprinted cells had survived the inkjet process (GFP production is here a clear indicator 1 day after printing).

This qualitative analysis was reinforced by a quantitative study of the cell viability using the TOX8 Resazurin-based in vitro assay. Figure $\mathbf{3 C}$ depicts the obtained results. As can be seen, although the present inkjet bioprinting process induced significant long-term alterations in the proliferation potential of cells (days 3 and 5) when compared to control cells, our hydrogelfree system does not significantly affect cell viability immediately after printing (day 1). In similar way, Blaeser et al. (2016) have stated that printing-induced shear stress does not only have an immediate impact on cell viability but also on their long term fate. Moreover, as shown in Figures 3D,E, a clear cell proliferation can be observed, 5 days after bioprinting, evidenced by a colonization of the inter-deposition space by the growing cells, leading to a quasi-confluent cell layer.

In order to fully demonstrate the potential of the developed technique, a 2-layer cell assembly was studied. Here, we applied our hydrogel-free bioprinting approach to directly and uniformly write two cellular layers on top of each other. The final goal being to overcome, through the use of inkjet deposition, the cell seeding variability issues usually experienced using traditional co-culture strategies for layer-by-layer deposition, particularly for population of sensitive cells (Reynolds et al., 2018).

To do so, we have first bioprinted a homogeneous layer of retina pigmented epithelium (RPE) on a GelMa biopaper and cultured them for 7 days $(229 \pm 19 \mu \mathrm{m}$ spot distance, $15 \mathrm{~nL}$ per spot). Then, once the RPE layer dense enough to cover all the biopaper surface, a second layer of NIH3T3 was printed following a tight deposition pattern $(210 \pm 12 \mu \mathrm{m}$ spot distance, $15 \mathrm{~nL}$ per spot), chosen to lead to a homogeneous second layer.

RPE cells were selected due to their ability to form cellular monolayer sheet (epithelium layer), a very good substrate for subsequent orientated cell attachment. Numerous studies have been heretofore carried out to model complex flat tissues by layerby-layer assembly techniques (Tang et al., 2006). For example, Matsusaki et al. (2007) fabricated a multilayer fibroblast construct by preparing fibronectin-gelatin nanofilms. In a similar way, Kawecki et al. (2018) applied human osseous cell sheet as living biopaper to support laser-assisted bioprinting of human endothelial cells.

RPE cells were printed with density of $110 \pm 15$ RPE cells per deposition, calculated according to their concentration as 

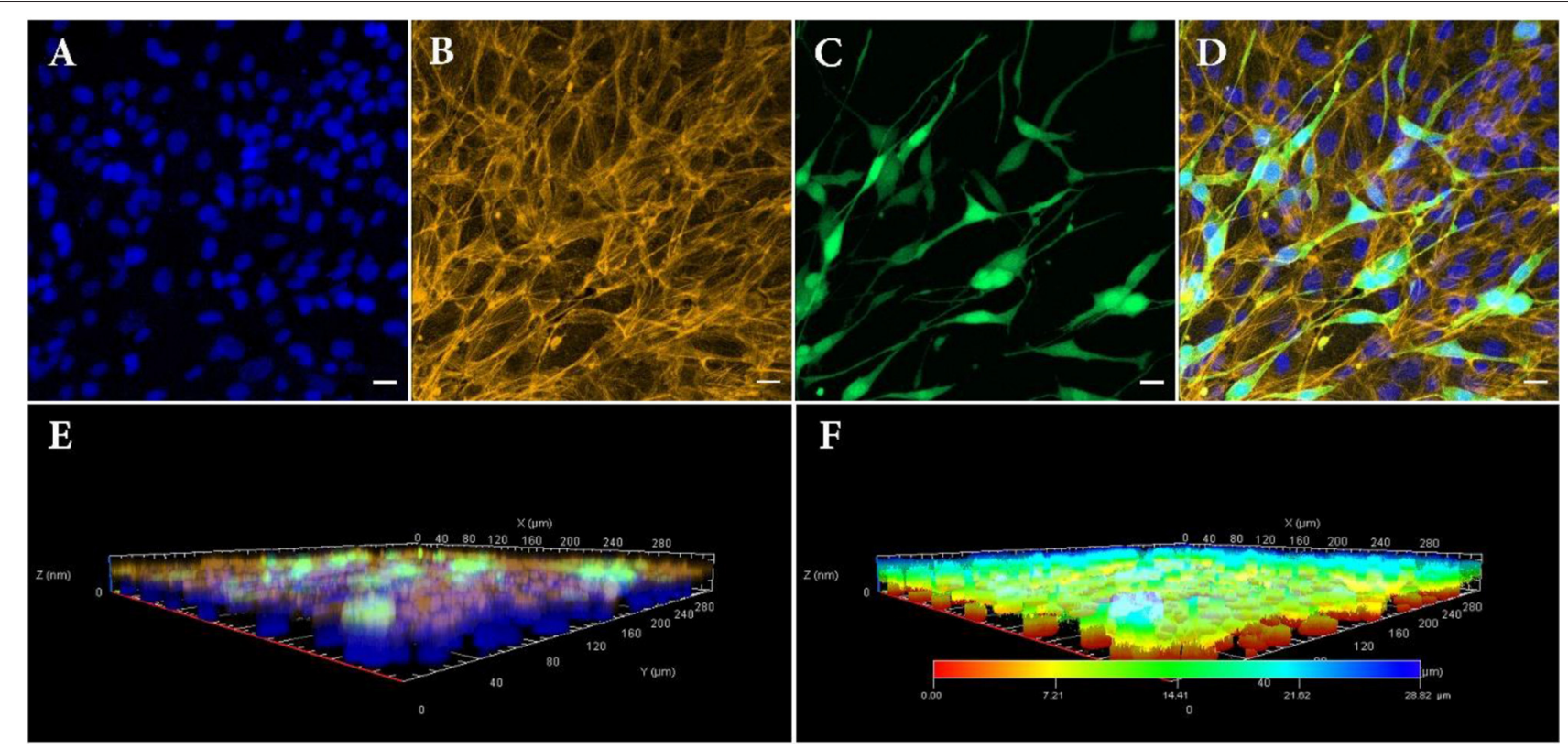

FIGURE 4 | Confocal fluorescence images of bilayer bioprinted construct. (A) Counterstained nuclei with DAPI (blue). (B) Actin filament staining with phalloidin (Yellow). (C) GFP positive NIH3T3 cells (Green). (D) Merged image. (E) 3D view and (F) depth coding of bilayer bioprinted construct. All images were captured on day 3 after printing of NIH3T3 or day 10 after printing RPE cells. Scale bars: $100 \mu \mathrm{m}$.

well as their size. One week after bioprinting, RPE cells formed a monolayer sheet, ready to be used as living biopaper for bioprinting NIH3T3 cells. Figures 4A-D depict the distribution of the two cell types 3 days after printing the second layer (i.e., 10 days after printing the first layer). As NIH3T3 cells are constitutively producing GFP, they are easily distinguished from RPE cells, especially in merged images (Figure $4 \mathrm{D}$ ).

As a matter of fact, RPE cells were homogeneously distributed as a dense layer over the GelMa surface whereas NIH3T3 cells randomly positioned themselves in a second and less dense layer (160 depositions against 324 depositions for RPE). Separate layers organization of printed cells was also confirmed with $3 \mathrm{D}$ confocal imaging (Figures $4 \mathrm{E}, \mathrm{F}$ ). Indeed, these images bring evidences that the RPE unlabeled cells (and their nuclei) have been localized in the lowest part of the construct, while GFP positive NIH3T3 cells can be found only on its upper layer. Moreover, depth coding of samples revealed that the full thickness of the construct is around $28.82 \mu \mathrm{m}$, consistent with cells' size (Figure 4F). Although size, shape and structure of RPE cells depend on age and location, average thickness of a RPE sheet in human is about $14 \mu \mathrm{m}$ (Forrester et al., 2016). Similarly, NIH3T3 cells size is estimated to be around $15 \mu \mathrm{m}$, leading to a theoretical 2-layer construct of $29 \mu \mathrm{m}$.

Overall, the capability to direct-write cell using a bioprinting strategy is not only a first step toward successful multilayer printing of dense cells but also a critical indicator of the feasibility of the envisioned organ printing technology. In the absence of a hydrogel ink, we can list the following impacts for the direct-write bioprinting method particularly from the viewpoint of cellular function and tissue remodeling.
First, as the most important point, cell-cell crosstalk is wellestablished, and the activation of notch signaling for regulating communication between neighboring cells can be guaranteed.

Second, bioprinting is performed with a high density of cells, which is particularly important for generating cell-rich tissue models. This breakthrough is directly dependent on the cell density within bioprinted construct. Indeed, different cells population behaviors, such as development capability and expression of differentiation factors are inefficient when only a small number of cells are present (Payne and You, 2014).

Finally, the ability to create heterogeneous layered models from different cell sources is another advantage of using cell suspensions as printing ink. Obviously, in hydrogel-based bioprinting systems, bioink properties, such as material type, surface tension and viscosity, shall be set according to the cell sources. Furthermore, shear tensions originated from high viscous hydrogels, may adversely affect cell viability.

Here we selected RPE and NIH3T3 cells just for proof-ofconcept study, and it is important that in the future, cells' type are being chosen according to the ultimate goal in a more physiologically relevant arrangement. In such case cell-cell communications can assure the transmission of vital molecular signals and trigger cell differentiation and remodeling. Future work by this approach may also look into successive printing of more than two cell layers.

\section{CONCLUSION}

It is now clear that bioprinting is a powerful technique with many potential applications for localizing biological components 
into 3D-engineered structures. Considerable progresses have been made and described in literatures to design and synthesize various hydrogel-based bioinks, compatible with living cells and their microenvironment. These models usually lack uniformity of printed cells and thereupon cannot completely establish immediate vital cellular communications for survival and remodeling of multicellular complex tissues. Another challenge related to application of hydrogels as bioink is that high viscosity of applied materials may generate high shear stress during cell deposition. Therefore, in the current study, we successfully replaced hydrogel ink with cell suspension and set size and distances between inkjet depositions. In this regards, not only no clogging occurred within the capillary nozzle, but also, the calculated maximum shear stress was relatively low. Moreover, thanks to the low viscosity of the cell suspension, we were able to print cells at high density (e.g., $110 \pm 15$ RPE cells per deposition). After adjusting density and uniformity of printed cells, current hydrogel-free bioprinting approach was extended to directly write two cellular layers on top of each other. To do so, we had first bioprinted a homogeneous epithelium layer, and once the cells covered all the surface, a second layer of cells was printed following first deposition pattern. Here we just applied two different cell sources (NIH3T3 and RPE cells) as models, but

\section{REFERENCES}

3d.FAB (2018). FLOWTIPS ${ }^{\circledR}$. Available online at: http://fabric-advanced-biology. univ-lyon1.fr/flowtips/ (accessed July, 2019).

Atala, A., Kasper, F. K., and Mikos, A. G. (2012). Engineering complex tissues. Sci. Transl. Med. 4:160rv112. doi: 10.1126/scitranslmed.3004890

Barron, J. A., Ringeisen, B. R., Kim, H., Spargo, B. J., and Chrisey, D. B. (2004). Application of laser printing to mammalian cells. Thin Solid Films 453, 383-387. doi: 10.1016/j.tsf.2003.11.161

Bertassoni, L. E., Cardoso, J. C., Manoharan, V., Cristino, A. L., Bhise, N. S., Araujo, W. A., et al. (2014). Direct-write bioprinting of cell-laden methacrylated gelatin hydrogels. Biofabrication 6:024105. doi: 10.1088/1758-5082/6/2/024105

Binder, K. W., Allen, A. J., Yoo, J. J., and Atala, A. (2011). Dropon-demand inkjet bioprinting: a primer. Gene Ther. Regul. 6, 33-49. doi: $10.1142 / S 1568558611000258$

Bishop, E. S., Mostafa, S., Pakvasa, M., Luu, H. H., Lee, M. J., Wolf, J. M., et al. (2017). 3-D bioprinting technologies in tissue engineering and regenerative medicine: current and future trends. Genes Dis. 4, 185-195. doi: 10.1016/j.gendis.2017.10.002

Blaeser, A., Duarte Campos, D. F., Puster, U., Richtering, W., Stevens, M. M., and Fischer, H. (2016). Controlling shear stress in 3D bioprinting is a key factor to balance printing resolution and stem cell integrity. Adv. Healthc. Mater. 5, 326-333. doi: 10.1002/adhm.201500677

Calvert, P. (2007). Printing cells. Science 318, 208-209. doi: $10.1126 /$ science. 1144212

Chimene, D., Lennox, K. K., Kaunas, R. R., and Gaharwar, A. K. (2016). Advanced bioinks for 3D printing: a materials science perspective. Ann. Biomed. Eng. 44, 2090-2102. doi: 10.1007/s10439-016-1638-y

Colosi, C., Shin, S. R., Manoharan, V., Massa, S., Costantini, M., Barbetta, A., et al. (2016). Microfluidic bioprinting of heterogeneous 3D tissue constructs using low-viscosity bioink. Adv. Mater. 28, 677-684. doi: 10.1002/adma.201503310

Daly, A. C., and Kelly, D. J. (2019). Biofabrication of spatially organised tissues by directing the growth of cellular spheroids within 3D printed polymeric microchambers. Biomaterials 197, 194-206. doi: 10.1016/j.biomaterials.2018.12.028

Derakhshanfar, S., Mbeleck, R., Xu, K., Zhang, X., Zhong, W., and Xing, M. (2018). 3D bioprinting for biomedical devices and tissue engineering: for clinical applications, cells must be targeted according to the ultimate goal. To sum up, such direct-write bioprinting strategy is a considerable step forward to the successful printing of complex multicellular tissues, where high density cell layers communicate with each other through direct contact.

\section{DATA AVAILABILITY STATEMENT}

All datasets generated for this study are included in the article/supplementary material.

\section{AUTHOR CONTRIBUTIONS}

EM and CM conceived and designed the experiments, performed the experiments, analyzed the data, and wrote the paper.

\section{ACKNOWLEDGMENTS}

Confocal Microscopy imaging were performed at the Center Technologique des Microstructures (University of Lyon, France) under the supervision of Christelle Fabrer-Boulé and Veronica La Padula. a review of recent trends and advances. Bioact. Mater. 3, 144-156. doi: 10.1016/j.bioactmat.2017.11.008

Desimone, E., Schacht, K., Jungst, T., Groll, J., and Scheibel, T. (2015). Biofabrication of 3D constructs: fabrication technologies and spider silk proteins as bioinks. Pure Appl. Chem. 87, 737-749. doi: 10.1515/pac-2015-0106

Forrester, J. V., Dick, A. D., Mcmenamin, P. G., Roberts, F., and Pearlman, E. (2016). "Chapter 1-anatomy of the eye and orbit," in The Eye (Fourth Edition), eds. J. V. Forrester, A. D. Dick, P. G. Mcmenamin, F. Roberts and E. Pearlman (W. B. Saunders), 1-102.e102.

Gao, B., Yang, Q., Zhao, X., Jin, G., Ma, Y., and Xu, F. (2016). 4D bioprinting for biomedical applications. Trends Biotechnol. 34, 746-756. doi: 10.1016/j.tibtech.2016.03.004

Guillotin, B., Souquet, A., Catros, S., Duocastella, M., Pippenger, B., Bellance, S., et al. (2010). Laser assisted bioprinting of engineered tissue with high cell density and microscale organization. Biomaterials 31, 7250-7256. doi: 10.1016/j.biomaterials.2010.05.055

Holzl, K., Lin, S., Tytgat, L., Van Vlierberghe, S., Gu, L., and Ovsianikov, A. (2016). Bioink properties before, during and after 3D bioprinting. Biofabrication 8:032002. doi: 10.1088/1758-5090/8/3/ 032002

Imani, R., Sh, H. E., Sharifi, A.-M., Baheiraei, N., and Fakhrzadeh, F. (2011). Evaluation of novel "biopaper" for cell and organ printing application: an in vitro study. J. Diabetes Metab. Disord. 10,1-13. Available online at: http://jdmd. tums.ac.ir/index.php/jdmd/article/view/290

Jakab, K., Norotte, C., Damon, B., Marga, F., Neagu, A., Besch-Williford, C. L., et al. (2008). Tissue engineering by self-assembly of cells printed into topologically defined structures. Tissue Eng. Part A 14, 413-421. doi: 10.1089/tea. 2007.0173

Jakab, K., Norotte, C., Marga, F., Murphy, K., Vunjak-Novakovic, G., and Forgacs, G. (2010). Tissue engineering by self-assembly and bio-printing of living cells. Biofabrication 2:022001. doi: 10.1088/1758-5082/2/2/022001

Kawecki, F., Clafshenkel, W. P., Auger, F. A., Bourget, J.-M., Fradette, J., and Devillard, R. (2018). Self-assembled human osseous cell sheets as living biopapers for the laser-assisted bioprinting of human endothelial cells. Biofabrication 10:035006. doi: 10.1088/1758-5090/aabd5b

Kilb, N., Herz, T., Burger, J., Woehrle, J., Meyer, P. A., and Roth, G. (2019). Protein Microarray Copying-Easy on-demand protein microarray 
generation compatible with fluorescence as well as label-free real-time analysis. ChemBioChem 20, 1554-1562. doi: 10.1002/cbic.201800699

Malda, J., Visser, J., Melchels, F. P., Jüngst, T., Hennink, W. E., Dhert, W. J., et al. (2013). 25th anniversary article: engineering hydrogels for biofabrication. $A d v$. Mater. 25, 5011-5028. doi: 10.1002/adma.201302042

Mandrycky, C., Wang, Z., Kim, K., and Kim, D.-H. (2016). 3D bioprinting for engineering complex tissues. Biotechnol. Adv. 34, 422-434. doi: 10.1016/j.biotechadv.2015.12.011

Marquette, C. A., Corgier, B. P., and Blum, L. J. (2012). Recent advances in multiplex immunoassays. Bioanalysis 4, 927-936. doi: 10.4155/bio.12.56

Masaeli, E., Forster, V., Picaud, S., Karamali, F., Nasr-Esfahani, M.-H., and Marquette, C. A. (2019). Tissue engineering of retina through high resolution 3dimentional inkjet bioprinting. Biofabrication. doi: 10.1088/1758-5090/ab4a20. [Epub ahead of print].

Matsunaga, Y. T., Morimoto, Y., and Takeuchi, S. (2011). Molding cell beads for rapid construction of macroscopic 3D tissue architecture. Adv. Mater. 23, H90-H94. doi: 10.1002/adma.201004375

Matsusaki, M., Kadowaki, K., Nakahara, Y., and Akashi, M. (2007). Fabrication of cellular multilayers with nanometer-sized extracellular matrix films. Angew. Chem. Int. Ed. 46, 4689-4692. doi: 10.1002/anie.200701089

Moroni, L., Boland, T., Burdick, J. A., De Maria, C., Derby, B., Forgacs, G., et al. (2018). Biofabrication: a guide to technology and terminology. Trends Biotechnol. 36, 384-402. doi: 10.1016/j.tibtech.2017.10.015

Mota, C., Puppi, D., Chiellini, F., and Chiellini, E. (2015). Additive manufacturing techniques for the production of tissue engineering constructs. J. Tissue Eng. Regen. Med. 9, 174-190. doi: 10.1002/term.1635

Nichol, J. W., Koshy, S. T., Bae, H., Hwang, C. M., Yamanlar, S., and Khademhosseini, A. (2010). Cell-laden microengineered gelatin methacrylate hydrogels. Biomaterials 31, 5536-5544. doi: 10.1016/j.biomaterials.2010.03.064

Nieponice, A., Soletti, L., Guan, J., Deasy, B. M., Huard, J., Wagner, W. R., et al. (2008). Development of a tissue-engineered vascular graft combining a biodegradable scaffold, muscle-derived stem cells and a rotational vacuum seeding technique. Biomaterials 29, 825-833. doi: 10.1016/j.biomaterials.2007.10.044

Norotte, C., Marga, F. S., Niklason, L. E., and Forgacs, G. (2009). Scaffold-free vascular tissue engineering using bioprinting. Biomaterials 30, 5910-5917. doi: 10.1016/j.biomaterials.2009.06.034

Onoe, H., and Takeuchi, S. (2015). Cell-laden microfibers for bottom-up tissue engineering. Drug Discov. Today 20, 236-246. doi: 10.1016/j.drudis.2014.10.018

Orive, G., Santos, E., Poncelet, D., Hernández, R. M., Pedraz, J. L., Wahlberg, L. U., et al. (2015). Cell encapsulation: technical and clinical advances. Trends Pharmacol. Sci. 36, 537-546. doi: 10.1016/j.tips.2015.05.003

Ozbolat, I. T. (2015). Scaffold-based or scaffold-free bioprinting: competing or complementing approaches? J. Nanotechnol. Eng. Med. 6:024701. doi: 10.1115/1.4030414

Payne, S., and You, L. (2014). Engineered cell-cell communication and its applications. Adv. Biochem. Eng. Biotechnol. 146, 97-121. doi: 10.1007/10_2013_249
Pirlo, R. K., Wu, P., Liu, J., and Ringeisen, B. (2012). PLGA/hydrogel biopapers as a stackable substrate for printing HUVEC networks via BioLP ${ }^{\mathrm{TM}}$. Biotechnol. Bioeng. 109, 262-273. doi: 10.1002/bit.23295

Pourchet, L. J., Thepot, A., Albouy, M., Courtial, E. J., Boher, A., Blum, L. J., et al. (2017). Human Skin 3D Bioprinting Using Scaffold-Free Approach. Adv. Healthc. Mater. 6:1601101. doi: 10.1002/adhm.201601101

Reynolds, P. M., Holzmann Rasmussen, C., Hansson, M., Dufva, M., Riehle, M. O., and Gadegaard, N. (2018). Controlling fluid flow to improve cell seeding uniformity. PLOS ONE 13:e0207211. doi: 10.1371/journal.pone. 0207211

Scherbahn, V., Nizamov, S., and Mirsky, V. M. (2016). Plasmonic detection and visualization of directed adsorption of charged single nanoparticles to patterned surfaces. Microchimica Acta 183, 2837-2845. doi: 10.1007/s00604-016-1956-7

Schulz, K., Pöhlmann, C., Dietrich, R., Märtlbauer, E., and Elßner, T. (2019). Electrochemical biochip assays based on anti-idiotypic antibodies for rapid and automated on-site detection of low molecular weight toxins. Front. Chem. 7:31. doi: 10.3389/fchem.2019.00031

Tang, Z., Wang, Y., Podsiadlo, P., and Kotov, N. A. (2006). Biomedical applications of layer-by-layer assembly: from biomimetics to tissue engineering. Adv. Mater. 18, 3203-3224. doi: 10.1002/adma.200600113

Tronser, T., Demir, K., Reischl, M., Bastmeyer, M., and Levkin, P. A. (2018). Droplet microarray: miniaturized platform for rapid formation and high-throughput screening of embryoid bodies. Lab Chip 18, 2257-2269. doi: 10.1039/C8LC00450A

Van Den Dolder, J., Spauwen, P. H., and Jansen, J. A. (2003). Evaluation of various seeding techniques for culturing osteogenic cells on titanium fiber mesh. Tissue Eng. 9, 315-325. doi: 10.1089/107632703764664783

$\mathrm{Xu}$, T., Jin, J., Gregory, C., Hickman, J. J., and Boland, T. (2005). Inkjet printing of viable mammalian cells. Biomaterials 26, 93-99. doi: 10.1016/j.biomaterials.2004.04.011

Yue, K., Trujillo-De Santiago, G., Alvarez, M. M., Tamayol, A., Annabi, N., and Khademhosseini, A. (2015). Synthesis, properties, and biomedical applications of gelatin methacryloyl (GelMA) hydrogels. Biomaterials 73, 254-271. doi: 10.1016/j.biomaterials.2015.08.045

Zhang, X., and Zhang, Y. (2015). Tissue engineering applications of three-dimensional bioprinting. Cell Biochem. Biophys. 72, 777-782. doi: $10.1007 / \mathrm{s} 12013-015-0531-\mathrm{x}$

Conflict of Interest: The authors declare that the research was conducted in the absence of any commercial or financial relationships that could be construed as a potential conflict of interest.

Copyright (C) 2020 Masaeli and Marquette. This is an open-access article distributed under the terms of the Creative Commons Attribution License (CC BY). The use, distribution or reproduction in other forums is permitted, provided the original author(s) and the copyright owner(s) are credited and that the original publication in this journal is cited, in accordance with accepted academic practice. No use, distribution or reproduction is permitted which does not comply with these terms. 